\title{
Topochemical Synthesis of Single-Crystalline Hydrogen-bonded Crosslinked Organic Frameworks and Their Guest-induced Elastic Expansion
}

\author{
Xuanfeng Jiang, ${ }^{\dagger} \ddagger, \uparrow$ Xunzhe Cui, ${ }^{\dagger} \neq$ Andrew J. E. Duncan, ${ }^{\dagger}, \ddagger$ Liang Li, ${ }^{\dagger}$ Russell P. Hughes, ${ }^{\dagger}$ Richard J. \\ Staples, $\$$ Eugeny V. Alexandrov,", I Davide M. Proserpio,\#, $\perp$ Yuyang Wu, \& Chenfeng Ke ${ }^{\dagger}{ }^{*}$ \\ † Department of Chemistry, Dartmouth College, 6128 Burke Laboratory, Hanover, New Hampshire, 03755 \\ ฯ Key Laboratory of Green Preparation and Application for Functional Materials, Ministry of Education, School of Ma- \\ terials Science and Engineering, Hubei University, Wuhan 430062, P.R. China \\ $\S$ Department of Chemistry, 578 S. Shaw Lane, Michigan State University, East Lansing, MI 48824 \\ \# Samara Center for Theoretical Material Science (SCTMS), Samara State Technical University, Molodogvardeyskaya \\ St. 244, Samara 443100, Russia \\ " Samara Center for Theoretical Material Science (SCTMS), Samara University, Moskovskoe shosse 34, 443086 Samara, \\ Russia \\ ${ }^{\perp}$ Dipartimento di Chimica, Università degli studi di Milano, Via C. Golgi 19, 20133 Milano, Italy. \\ \& IMSERC, Department of Chemistry, Northwestern University, 2145 Sheridan Road, Evanston, IL 60208
}

\begin{abstract}
Covalently linked single-crystalline porous organic materials are highly desired for structure-property analysis, however, periodically polymerizing organic entities into high dimensional networks is challenging. Here, we report a series of topologically divergent single-crystalline hydrogen-bonded crosslinked organic frameworks ( $\left.\mathrm{H}_{\mathrm{C}} \mathrm{OFs}\right)$ with visible guestinduced elastic expansions, which mutually integrate high structural order and high flexibility into one framework. These $\mathrm{H}_{\mathrm{C}} \mathrm{OFs}$ are synthesized by photo-crosslinking molecular crystals with alkyldithiols of different chain lengths. Their detailed structural information was revealed by single-crystal X-ray analysis and experimental investigations of $\mathrm{H}_{\mathrm{c}} \mathrm{OFs}$ and their corresponding single-crystalline analogues. Upon guest adsorption, $\mathrm{H}_{\mathrm{C}} \mathrm{OF}-2$ crystals comprised of a 3D self-entangled polymer network undergo anisotropic expansion to more than twice their original size, while the 2D-bilayer $\mathrm{H}_{\mathrm{C}} \mathrm{OF}-3$ crystals exhibit visible, layered sorption bands and form delaminated sheets along the plane of its 2D layers. The dynamic expansion of $\mathrm{HcOF}$ networks creates guest-induced porosity with over $473 \%$ greater volume than their permanent voids, as calculated from their record-breaking aqueous iodine adsorption capacities. Temperature-gated DMSO sorption investigations illustrated that the flexible nature of crosslinkers in $\mathrm{H}_{\mathrm{C}} \mathrm{OFs}$ provides positive entropy from the co-existence of multiple conformations to allow for elastic expansion and contraction of the frameworks.
\end{abstract}

\section{Introduction}

Covalently-linked single-crystalline porous organic materials, ${ }^{1-4}$ compared to the coordination-driven assembly of their metal-organic framework (MOF) counterparts, ${ }^{5}$ are rare due to the synthetic challenges of polymerizing monomers into higher-dimensional networks (i.e. 2D and 3D) with precise long-range order. Sustained research efforts have been devoted to the development of single-crystalline porous organic polymers, since their resolved single-crystal structures will provide an atomic-level understanding of the structure-property relationship between the architectures of porous organic polymers and their sorbates. One approach, demonstrated in the syntheses of single-crystalline covalent organic frameworks (COFs), is the ultra-fine optimization of the reversible polymerization-crystallization evolution (e.g. nitrosyl dimerization, ${ }^{2}$ boronic ester formation, ${ }^{3}$ and imine condensation ${ }^{4}$ ), despite the reversible nature of the crosslinking reactions posing limitations in their chemical stability. Another approach to the development of porous materials which has not yet been demonstrated, is the topochemical polymerization of monomers into single-crystalline $1 \mathrm{D}^{6,7}$ and $2 \mathrm{D}^{8,9}$ polymers through a single-crystal to single-crystal (SCSC) transformation. The precise crystal engineering prerequisite of placing reactive motifs in close proximity, however, limits the scope of available monomers. Since rigid molecular entities connected by covalent bonds are critical to a predictable high dimensional polymerization, these single crystalline COFs and 2D polymers only tolerate a limited degree of structural variation, ${ }^{10,11}$ unlike flexible MOFs ${ }^{12-15}$ constructed with more pliable coordination bonds.

While high structural order and high flexibility are not mutually exclusive, ${ }^{16}$ simultaneous integration of these features into porous polymers becomes particularly challenging. ${ }^{17,18}$ To this end, a different approach that polymerizes reactive motifs in a monomer single crystal with crosslinkers that are heterogeneously diffused into the host lattice 


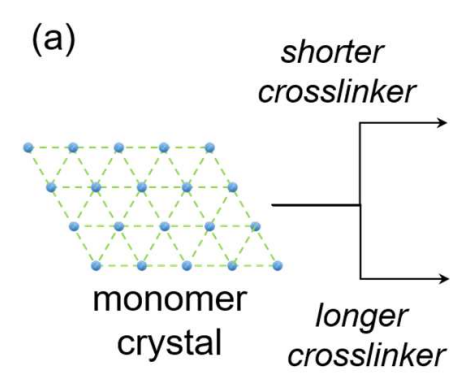

(b)

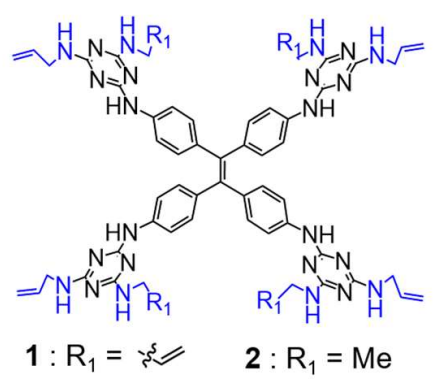

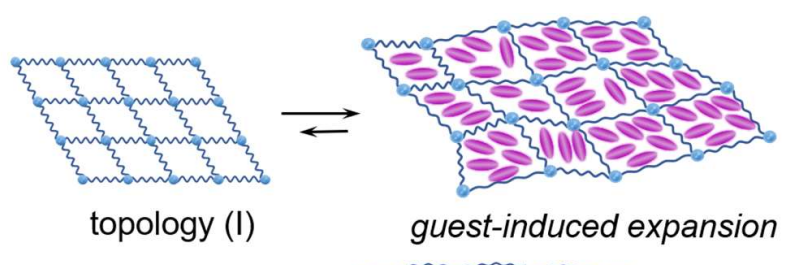

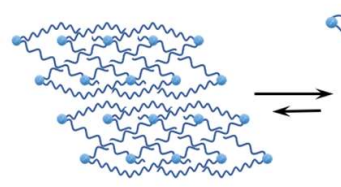

topology (II)

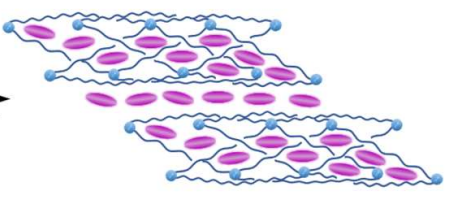

guest-induced expansion

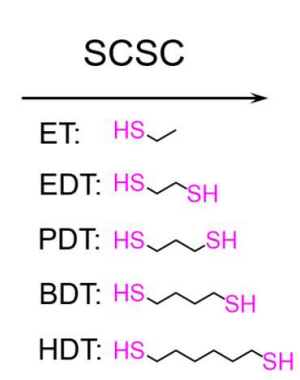

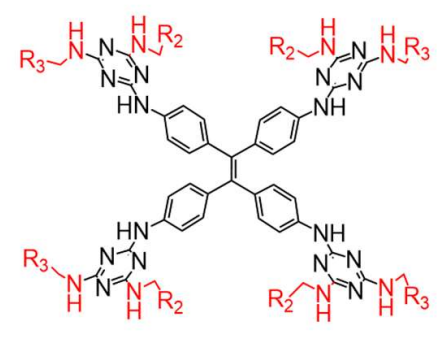

$\mathrm{H}_{\mathrm{C}} \mathrm{OFs}-2-4$ and P5-P8

\begin{tabular}{|c|c|c|c|c|}
\hline monomer & thiols & products & $\mathrm{R}_{2}=$, and $\mathrm{R}_{3}=$ & allyl/thioether \\
\hline \multirow[t]{3}{*}{1} & EDT & $\mathrm{H}_{\mathrm{C}} \mathrm{OF}-2$ & 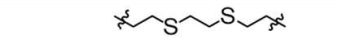 & $0 / 8$ \\
\hline & PDT & $\mathrm{H}_{\mathrm{C}} \mathrm{OF}-3$ & 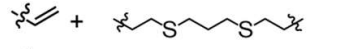 & $2 / 6$ \\
\hline & BDT & $\mathrm{H}_{\mathrm{C}} \mathrm{OF}-4$ & 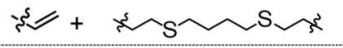 & $3 / 5$ \\
\hline 2 & EDT & P5 & 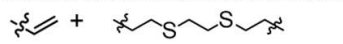 & $2 / 2$ \\
\hline \multirow[t]{3}{*}{$\left(R_{3}=M e\right)$} & PDT & P6 & 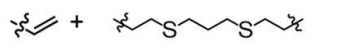 & $2 / 2$ \\
\hline & BDT & P7 & 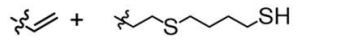 & $2 / 2$ \\
\hline & HDT & P8 & 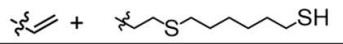 & $2.5 / 1.5$ \\
\hline
\end{tabular}

Figure 1. Design and topochemical synthesis of $\mathrm{H}_{\mathrm{C}} \mathrm{OFs}$ and polymers via SCSC thiol-ene polymerization. (a) Schematic representation of crosslinker-dependent topological divergence and corresponding differences in guest sorption in $\mathrm{H}_{\mathrm{C}} \mathrm{OFs}-2-4$. (b) General synthetic scheme for topochemical SCSC synthesis of HcOFs-2-4, P5-P8, and tabulation of products with allyl/thioether ratios determined by NMR spectroscopy and elemental analysis.

will provide a unique opportunity to overcome this obstacle and generate single-crystalline porous organic polymers with designed dynamic sorption behaviors. These monomers are pre-organized by hydrogen bonding interactions in the solid state similar to those hydrogen-bonded organic framework $^{19-23}$ (HOF) materials, which are photo-crosslinked subsequently via thiol-ene ${ }^{1}$ and thiol-yne ${ }^{24}$ reactions. The feasibility of this approach was first demonstrated ${ }^{1}$ by Wuest et al., and later the dynamic sorption behavior ${ }^{24}$ of the obtained porous crystals was discovered by us. Notably, such SCSC transformations can employ flexible crosslinkers, such as alkyldithiols, in contrast to conventional COF synthesis ${ }^{25-28}$ or topochemical polymerization, ${ }^{29}$ which utilize rigid building blocks. The flexibility of these dithiols encapsulates a design paradox: on one hand, their flexibility enables extensive diffusion and crosslinking; on the other hand, the resulting flexible linkages post challenges for single crystal X-ray diffraction (SCXRD) analysis. In essence, this method demands careful balance of the properties that facilitate both dynamic structural variation and the ability to characterize the detailed polymer network architecture and crosslinking topology. So far, the lack of clearly defined polymer architectures has limited the understanding of their dynamic sorption behavior to little more than empirical observation.

In this report, we demonstrate a comprehensive investigation on the development of single crystalline hydrogenbonded crosslinked organic frameworks ( $\mathrm{H}_{\mathrm{C}} \mathrm{OFs}$ ) by photocrosslinking of molecular crystals with alkyldithiols of different chain lengths (Figure 1). We reveal the first topologically divergent topochemical synthesis of $\mathrm{H}_{\mathrm{C}} \mathrm{OFs}$ synthesized from the same crystalline monomer. The synthesis of a series of oligomeric and polymeric analogues (i.e. P5-P6) with a decreased number of crosslinking motifs, and comparison to the corresponding $\mathrm{H}_{\mathrm{C}} \mathrm{OFs}$, revealed detailed structural information which allowed for the determination of the crosslinking topologies of the $\mathrm{H}_{\mathrm{C}} \mathrm{OFs}$ for the first time. Remarkably, different crosslinking topologies of these $\mathrm{HcOFs}$ lead to notably distinctive guest sorption properties (Figure 1a). Upon $\mathrm{I}_{2}$ and temperature-gated DMSO adsorption, $\mathrm{H}_{\mathrm{c}} \mathrm{OF}-2$ crystals comprised of a 3D self-entangled polymer network undergo anisotropic expansion to more than 

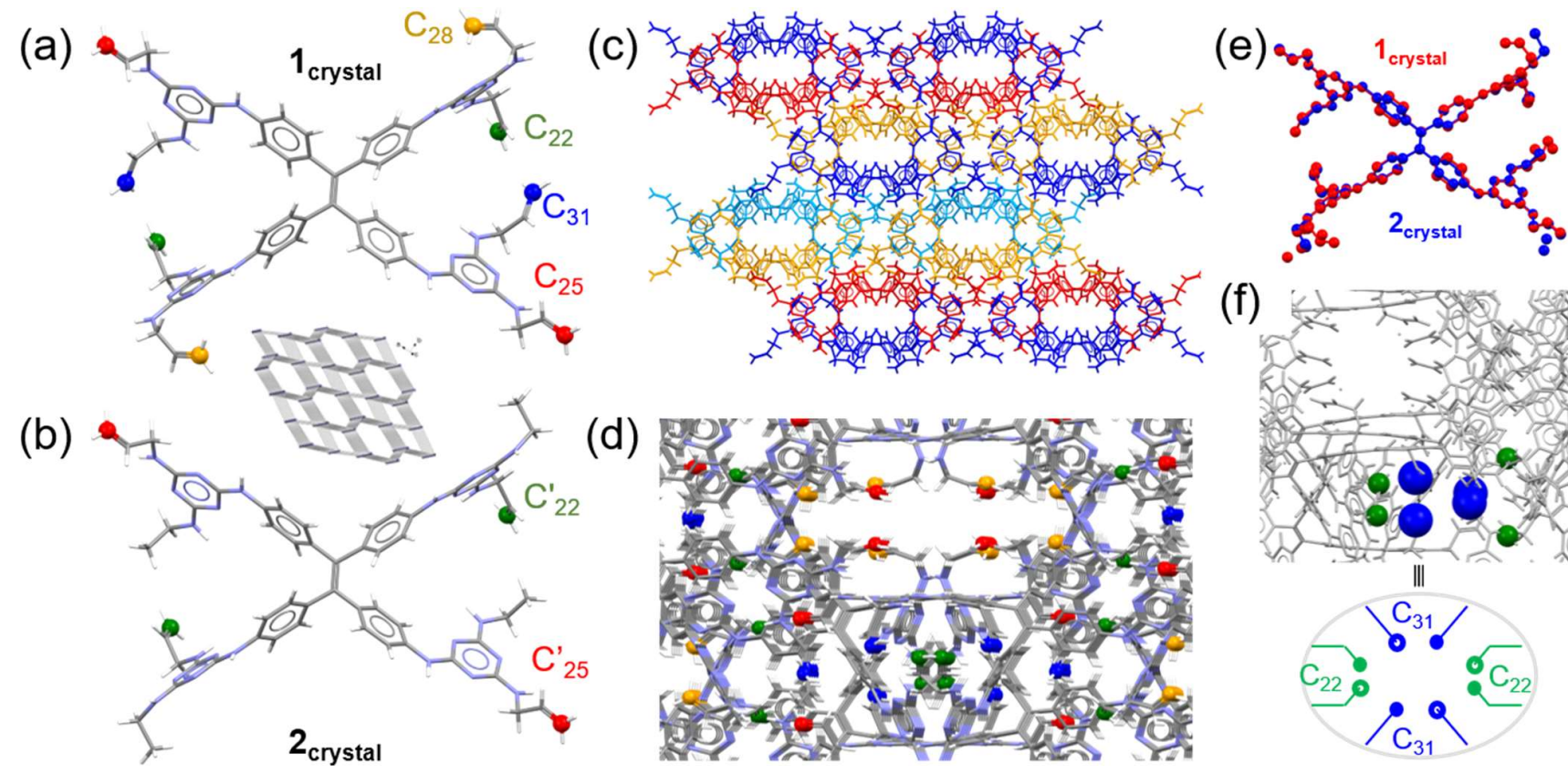

Figure 2. (a-b) Crystal structures and packing diagram of isomorphous (a) $\mathbf{1}_{\text {crystal }}$ and (b) $\mathbf{2}_{\text {crystal viewed along the [110] direction }}$ with simplified underlying six-connected (6-c) net topology (snw, inset). The terminal alkene atoms are color coded to highlight

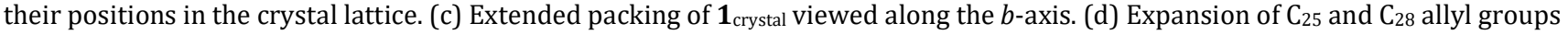
lining hexagonal pore and congested $\mathrm{C}_{22} / \mathrm{C}_{31}$ junction. (e) Structural overlay of $\mathbf{1}_{\text {crystal }} / \mathbf{2}_{\text {crystal }}$ based on calculated RMSD of atomic positions. (f) Highlight of congested $\mathrm{C}_{22} / \mathrm{C}_{31}$ crosslinking junction with simplified cartoon representation.

twice their original size, induced by strong substrate-framework interactions. The 2D-bilayer HcOF-3 crystals exhibit visible, layered sorption bands and form delaminated sheets along the plane of its $2 \mathrm{D}$ layers. The dynamic expansion of $\mathrm{H}_{\mathrm{C}} \mathrm{OF}$ networks creates guest-induced porosity, which are calculated from their record-breaking iodine adsorption capacities measured in aqueous environment, of more than $473 \%$ greater than their permanent voids. We also reveal that the flexible nature of crosslinkers in $\mathrm{H}_{\mathrm{C}} \mathrm{OFs}-$ 2-4 provides positive entropy from the co-existence of multiple conformations to allow for elastic contraction of the framework during desorption. These results not only provide a practical approach to achieve high structural order and flexibility in topologically diverse porous organic frameworks, but also enlighten a path for the design of porous organic materials with large guest-induced voids that promise high guest adsorption capacity and selectivity.

\section{Results and Discussions}

Monomers 1 and 2, possessing tetraphenylethylene (TPE) cores with four melamine hydrogen bonding moieties, are synthesized from $\mathbf{S 1}$ through a stepwise nucleophilic substitution with allylamine and ethylamine ${ }^{24}$ (Figure $1 \mathrm{~b}$, Scheme S1). Compared to monomer 1 with eight allyl groups, four ethyl groups on the melamine arms of 2 reduce the number of reactive allyl groups while maintaining a similar spatial occupancy. Slow vapor diffusion of $\mathrm{MeCN}$ into DMF solutions of these monomers produced isomorphous $\mathbf{1}_{\text {crystal }}$ and $\mathbf{2}_{\text {crystal }}$ in the orthorhombic space group Fddd with nearly identical unit cell parameters $(0.8 \%$ difference, Table S3) and packing conformations (Figure 2a-b). In the SCXRD analysis, each monomer interacts with six neighboring monomers through a total of $20 \mathrm{~N}-\mathrm{H} \cdots \mathrm{N}$ hydrogen bonds formed between their melamine moieties to construct a 3D hydrogen-bonded framework (Figures 2c-d, S37-38). The solvent-filled void spaces of $\mathbf{1}_{\text {crystal }}$ and $\mathbf{2}_{\text {crystal }}$ comprise $21.4 \%$ and $23.0 \%$ of the unit cell volumes, respectively, with 3D open channels exhibiting hexagonal cross sections along the [110] and [1̄ㅣㄹ directions (Figure 2d). The inter-connected 3D channels (Figure S39), suitable pore sizes, and $\mathrm{NH}$-decorated pore surfaces of $\mathbf{1}_{\text {crystal }}$ and $\boldsymbol{2}_{\text {crystal }}$ allow for extensive diffusion and assembly of linear alkyldithiols throughout the crystals via van der Waals and hydrogen bonding interactions.

From the [110] and [1 10$]$ perspectives, there are two types of allyl terminal atoms $\left(\mathrm{C}_{25}\right.$, red and $\mathrm{C}_{28}$, yellow, Figure $2 d$ ) located along the hexagonal pore surfaces in $\mathbf{1}_{\text {crystal }}$ (see Table S6 for C …C distances). From the [010] perspective, symmetrically related terminal allyl atoms $\left(\mathrm{C}_{31}\right.$, blue, Figure 2f) are packed tightly in a clustered junction and are slightly removed from the pore surface. Allyl terminal atoms $\mathrm{C}_{22}$ (green, Figure 2f) are found surrounding the clustered junction and are the least accessible set of allyl groups of monomer 1 as suggested by SCXRD analysis. The spatial distribution of allyl groups of $\boldsymbol{2}_{\text {crystal }}$ are similar to those of $\mathbf{1}_{\text {crystal, }}$ in which allyl terminal atoms (Figure $2 b, C_{25}^{\prime}$, red) are located along the hexagonal pore surfaces and the $\mathrm{C}_{22}$-allyl groups (Figure $2 b$, green) in $\mathbf{2}_{\text {crystal }}$ are packed nearly identically to those of the $\mathrm{C}_{22}$-allyl groups in $\mathbf{1}_{\text {crystal. }}$.

To quantitatively assess the accessibility and kinetic reactivity differences of these allyl groups in the solid state, ethanethiol (ET) was used as a thiol-ene probe, which was diffused into $\mathbf{1}_{\text {crystal }}$ and $\mathbf{2}_{\text {crystal }}$ followed by UV irradiation. At different ET diffusion times, averages of $4.8 \pm 0.2(3 \mathrm{~d})$ and $6.7 \pm 0.2(14 \mathrm{~d})$ of the eight allyl groups of 1 were converted 

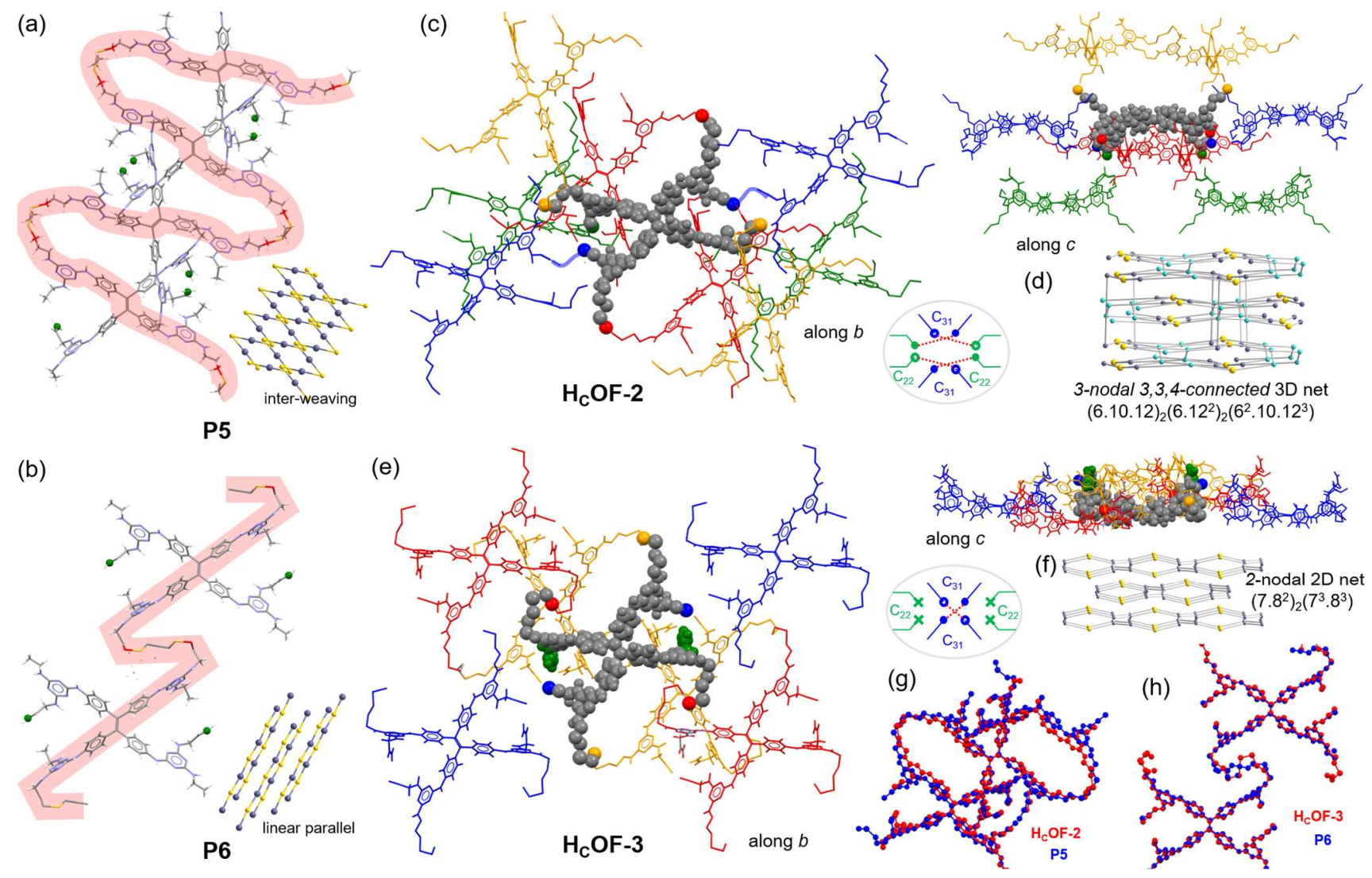

(6.10.12) $\left(6.12^{2}\right)_{2}\left(6^{2} \cdot 10.12^{3}\right)$

Figure 3. (a-b) Crystal structures of (a) P5 and (b) P6 with polymer backbones highlighted in red and polymer topology inset. (c) Packing diagrams of $\mathrm{H}_{\mathrm{C}} \mathrm{OF}-2$ highlighting the local environment of a tetramelamine-TPE repeating unit (spacefill) viewed along the $b$ - and $c$-axes and schematic of crosslinking junction (cartoon inset). Neighboring repeating units (sticks) are colored according to the corresponding allyl carbon to which they are crosslinked (red $-\mathrm{C}_{25}$, yellow $-\mathrm{C}_{28}$, blue $-\mathrm{C}_{31}$, green $-\mathrm{C}_{22}$ ). (d) Calculated topology of HcOF-2 with TPE (yellow ball) and two topologically distinct melamines (cyan and blue balls). (e) Local packing environment of $\mathrm{H}_{\mathrm{C}} \mathrm{OF}-3$ repeating units viewed along the $b$ - and $c$-axes with schematic of crosslinking junction (cartoon inset). (f) Calculated topology of $\mathrm{H}_{\mathrm{C}} \mathrm{OF}-3$ with TPE (yellow ball) and melamine moieties (blue ball). (g-h) Structural overlays of (g) $\mathrm{H}_{\mathrm{C}} \mathrm{OF}-2 / \mathbf{P 5}$ and (h) HCOF-3/P6 based on calculated RMSD of atomic positions.

to thioethers (Figure S23), as determined by ${ }^{1} \mathrm{H}$ NMR spectroscopy. Products with four to eight ET substitutions $([\mathbf{1} \bullet(4-8) E T])$ were identified in the mass spectrum (Figure S21), which revealed a trend of decreasing relative abundance with greater number of substitutions. When $\mathbf{2}_{\text {crystal }}$ was subjected to ET substitution, an average of $3.0 \pm 0.1$ out of four allyl groups were consumed (Figure S26), producing a mixture of species with two to four ET substitutions ([2• (2-4)ET], Figure S22). These experiments confirmed the ET accessibility of all allyl groups in $\mathbf{1}_{\text {crystal }}$ and $\mathbf{2}_{\text {crystal }}$ and suggested that $\mathrm{C}_{25} / \mathrm{C}_{25^{-}}$, and $\mathrm{C}_{28} / \mathrm{C}_{28}^{\prime}$-allyl groups along the pore surfaces are more reactive. When the ET substitution was kinetically controlled (Table S2), crystal samples composed of largely [1•(3-4)ET], and trace amounts of other derivatives with an average of $3.8 \pm 0.4$ allyl-to-thioether conversion were being consistently produced.

Flexible alkyldithiols $\left(\left(\mathrm{HS}\left(\mathrm{CH}_{2}\right)_{n} \mathrm{CH}_{2} \mathrm{SH}\right)\right.$, including ethanedithiol $(n=1, E D T)$, propanedithiol $(n=2$, PDT), and butanedithiol $(n=3, B D T)$, are employed as crosslinkers for the synthesis of $\mathrm{H}_{\mathrm{C}} \mathrm{OFs}$. To mitigate variation in diffusion kinetics, moderate concentrations of alkyldithiol solutions were introduced to the crystals in the dark in three portions followed by UV irradiation, extensive washing, and supercritical $\mathrm{CO}_{2}$ activation to afford insoluble single-crystalline $\mathrm{H}_{\mathrm{C}} \mathrm{OF}-2, \mathrm{H}_{\mathrm{C}} \mathrm{OF}-3$, and $\mathrm{H}_{\mathrm{C}} \mathrm{OF}-4$, respectively. ${ }^{30}$ No residual free thiol signal was recorded in the FT-IR and Raman spectra (Figures S66-71) and carbon resonances attributed to dithioether moieties were identified in the aliphatic region (30$45 \mathrm{ppm}$ ) of the solid-state ${ }^{13} \mathrm{C}$ NMR spectra of HcOFs-2-4 (Figures S18-20), suggesting a complete dithiol-to-dithioether conversion. Although the alkene carbon resonances of 1 disappeared in $\mathrm{H}_{\mathrm{C}} \mathrm{OF}-2$, residual alkene carbon resonances recorded in $\mathrm{H}_{\mathrm{c}} \mathrm{OF}-3$ and $\mathrm{H}_{\mathrm{C}} \mathrm{OF}-4$ suggest some allyl groups remain unreacted after crosslinking. Averaged monomer-to-crosslinker ratios in the supercritical $\mathrm{CO}_{2}-$ activated $\mathrm{H}_{\mathrm{C}} \mathrm{OFs}-2-4$ were revealed by elemental analysis (Table S1) as (3.98 \pm 0.13)EDT: 1 in HCOF-2, (2.97 \pm 0.03)PDT: 1 in HcOF-3, and (2.53 \pm 0.03$)$ BDT: 1 in HcOF-4, suggesting approximately two and three out of eight allyl groups in 1 remain unreacted in $\mathrm{H}_{\mathrm{c}} \mathrm{OF}-3$ and $\mathrm{H}_{\mathrm{c}} \mathrm{OF}-4$, respectively.

When alkyldithiols were diffused into $\boldsymbol{2}_{\text {crystal, the soluble }}$ crystal samples P5-P8 were obtained after photo-irradiation. ${ }^{31}$ Dynamic light scattering (DLS, Figure S36) analysis suggests P5-P8 are composed of polymeric and oligomeric 
species, in which polymers are the major components of P5 $(\mathrm{r} \sim 50 \mathrm{~nm})$ and $\mathbf{P 6}(\mathrm{r} \sim 70 \mathrm{~nm})$ whereas oligomers are the dominate species in P7 ( $\mathrm{r} \sim 3-4 \mathrm{~nm})$ and $\mathbf{P 8}(\mathrm{r} \sim 3-4 \mathrm{~nm})$. In the NMR analysis (Figures S30-35), dithioethers ($\left.\mathrm{S}\left(\mathrm{CH}_{2}\right)_{\mathrm{n}} \mathrm{CH}_{2} \mathrm{~S}-, \mathrm{n}=1,2\right)$ are found as the major species in $\mathbf{P 5}$

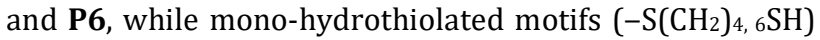
were abundant in $\mathbf{P 7}$ and $\mathbf{P 8}$. These results indicate that dithioether crosslinking motifs were consistently formed between periodically aligned pairs of alkenes in the solid-state in P5 and P6. In contrast, a mismatched alkene-to-dithiol distance will lead to a rapid decrease in the degree of polymerization and generate oligomeric species, as was observed in $\mathbf{P 7}$ and $\mathbf{P 8}$.

Transparent light-yellow crystals of $\mathrm{H}_{\mathrm{C}} \mathrm{OF}-2-4$ and P5-P7 were found to retain the orthorhombic space group Fddd by SCXRD analysis (P8 did not diffract well). Compared to $\mathbf{1}_{\text {crys- }}$ tal, $\mathrm{H}_{\mathrm{C}} \mathrm{OFs}-2-4$ demonstrate $2.7 \%,-1.9 \%$, and $1.5 \%$ changes in unit cell volume, respectively (Tables S5). Compared to 2 crystal, P5-P7 demonstrate $-2.3 \%,-0.4 \%$, and $-1.3 \%$ changes in unit cell volume, respectively (Tables S4). Refinement of the TPE-melamine entity for HcOFs-2-4 and P5P7 is straight forward, which allows for conformational comparisons to those of the monomers by calculation of the root mean square deviation (RMSD) of atomic positions. RMSD analysis (Table S8) reveals that the melamine-TPE scaffold of the HcOFs and P5-P7 possess nearly identical conformations to their corresponding monomer crystals in the solid state. Among them, the melamine-TPE scaffolds of $\mathrm{H}_{\mathrm{C}} \mathrm{OF}-3$ and $\mathbf{P 6}$ showed the lowest deviation, suggesting PDT crosslinking can be facilitated with the least perturbation of the framework structure.

In HcOF-2-3 and P5-P6, electron density consistent with the presence of dithioethers are observed between the allyl groups $\left(\mathrm{C}_{25}, \mathrm{C}_{28}\right.$, and $\left.\mathrm{C}_{25}{ }_{25}\right)$ in the hexagonal pores described in $\mathbf{1}_{\text {crystal }}$ and $\mathbf{2}_{\text {crystal. }}$ Refinement of the electron density revealed one conformer of the dithioether moieties in $\mathrm{H}_{\mathrm{C}} \mathrm{OF}-2$ and $\mathrm{H}_{\mathrm{C}} \mathrm{OF}-3, \mathbf{P 5}$ and $\mathbf{P 6}$, while residual electron density in close proximity suggests the existence of multiple conformers. The disorder of dithioether moieties in $\mathrm{HcOF}_{\mathrm{C}} \mathrm{-}$ and $\mathbf{P 7}$ is too severe for reliable structural analysis. Since $\mathbf{1}_{\text {crystal }}$ and $\mathbf{2}_{\text {crystal }}$ are isomorphous, comparisons between the X-ray structures of the $\mathrm{H}_{\mathrm{C}} \mathrm{OFs}$ and their analogous polymers, i.e. $\mathrm{H}_{\mathrm{C}} \mathrm{OF}-2$ with P5, etc., could confirm the accuracy of the refined cross-linking chains. As shown in Figure 3a, an Sshaped linear polymer P5 was found with ethanedithioethers bridging the $\mathrm{C}_{25}{ }_{25}$-allyl groups of two monomer 2 that are packed in two neighboring layers angled at $120^{\circ}$ relative to each other along the [010] direction. These S-shaped polymers then weave into each other along the [001] direction (Figure S42). In contrast, a Z-shaped linear polymer P6 was formed (Figure $3 \mathrm{~b}$ ) with propanedithioethers connecting the $\mathrm{C}_{25}$-allyl groups of two different monomer $\mathbf{2}$ that are packed in parallel in the same layer along the [010] direction. The $\mathrm{C}_{22}$-allyl groups of $\mathbf{P 5}$ and $\mathbf{P 6}$ remained unreacted and their atomic positions are found nearly identical to that of $\mathbf{2}_{\text {crystal }}$ in RMSD analysis (Table S8). The conclusion from the SCXRD analysis of P5 and P6 is consistent with the formation of linear $1 \mathrm{D}$ polymers, as was suggested by NMR and DLS analysis (Figures S30-36).

In $\mathrm{H}_{\mathrm{C}} \mathrm{OF}-2$, a set of $\mathrm{S}$-shaped dithioether linkages in similar positions to those of P5 were first identified (red, Figure 3c) between two $\mathrm{C}_{25}$-allyl groups in $\mathbf{1}_{\text {crystal. }}$ The second set of $\Omega$ shaped dithioether linkages were identified between $\mathrm{C}_{28}$-allyl groups of monomer $\mathbf{1}$ packed in non-adjacent layers along the $c$-axis (yellow, Figure 3c, right). In $\mathrm{HcOF}_{\mathrm{C}} 3$ (Figure $3 e$ ), a set of Z-shaped dithioether linkages (red) that are similar to those of $\mathbf{P 6}$ were identified between $\mathrm{C}_{25}$-allyl groups of monomer $\mathbf{1}$. Another set of S-shaped dithiother linkages (yellow, Figure $3 \mathrm{e}$ ) were identified between $\mathrm{C}_{28}$-allyl groups of monomer 1 that are packed in two neighboring layers also angled at $120^{\circ}$ relative to each other. $\mathrm{C}_{22}$-allyl groups of 1 remained unreacted in $\mathrm{H}_{\mathrm{C}} \mathrm{OF}-3$ (green, spacefill, Figure 3e), which are consistent with our elemental analysis and solid-state NMR results. Although identifying the diethioether moieties between the symmetry-related $\mathrm{C}_{22}$ and $\mathrm{C}_{31}$ atoms of $\mathrm{H}_{\mathrm{C}} \mathrm{OF}-2$ and $\mathrm{H}_{\mathrm{C}} \mathrm{OF}-3$ (formerly $\mathrm{C}_{22}$ and $\mathrm{C}_{31}$ allyl groups of 1) could reveal the crosslinking topologies of $\mathrm{H}_{\mathrm{C}} \mathrm{OF}-2$ and $\mathrm{H}_{\mathrm{C}} \mathrm{OF}-3$, refinement of the existing residual electron density around the clustered junction cannot provide unambiguous atomic positions of these linking motifs and, therefore a complete topological assignment is yet to be determined.

Due to the ambiguity of the residual electron density between the $\mathrm{C}_{22}$ and $\mathrm{C}_{31}$ atoms, SCXRD analysis suggests there may exist seven and three crosslinking possibilities (Scheme S5) for $\mathrm{H}_{\mathrm{C}} \mathrm{OF}-2$ and $\mathrm{H}_{\mathrm{C}} \mathrm{OF}-3$, respectively. ETsubstituted $\mathbf{1}_{\text {crystal, }}$ composed of largely [1-(3-4)ET] with blocked $\mathrm{C}_{25}$ - and $\mathrm{C}_{28}$-allyl sites, was employed to reveal the crosslinking taking place at the clustered junction. When $[1 \cdot(3-4) E T]$ crystals were soaked in neat EDT followed by photo-irradiation, surprisingly, a majority of the EDTreacted crystal samples were soluble in DMSO- $d_{6}$. The ${ }^{1} \mathrm{H}$ NMR spectrum (Figure S44a) suggests that approximately two allyl groups out of the four residual ones were reacted. Neither polymeric nor oligomeric species were detected in DLS, and monomeric species of [1•(3-4)ET•2EDT] were observed in mass spectrum analysis (Figure S45-46). These crystals were washed extensively to remove EDT and were re-subjected to UV-irradiation. This time, the product became insoluble crystals, indicating the formation of a crosslinked polymer network and an extensive allyl-to-thioether conversion. Among the seven linking possibilities, only the connection between non-adjacent $\mathrm{C}_{22}$ - and $\mathrm{C}_{31}$-allyl groups (Figure 3c, inset) matches the experimental outcomes (see the SI for detailed analysis, page S55-59). That is, the $\mathrm{C}_{31-}$ allyl groups of $\mathbf{1}$ were substituted with two equivalent EDT in the junction area first, forming soluble monomeric species. The remaining thiol groups subsequently reacted with the non-adjacent $\mathrm{C}_{22}$-allyl groups to form insoluble interlocked 2D networks. When PDT was diffused into [1・ 3 4)ET] crystals, the photo-irradiated crystals were completely soluble in DMSO- $d_{6}$, leaving two unreacted allyl groups and forming linear polymeric species revealed by NMR and DLS analysis (Figures S47-48). The experimental evidence and SCXRD analysis suggest that a homotopiccrosslinking had taken place between $\mathrm{C}_{31}$-allyl groups (Figure 3e, inset, see the SI for detailed analysis, page S61-62), connecting monomers packed in parallel in the same layer. These analyses complement the SCXRD data and allow for topological determination of the complete $\mathrm{H}_{\mathrm{C}} \mathrm{OF}-2$ and $\mathrm{HcOF}-3$ structures. The fully resolved crosslinking topology of $\mathrm{H}_{\mathrm{C}} \mathrm{OF}-2$ is revealed to be a 3D interconnected polymer network (Figure $3 \mathrm{~d}$ ), and $\mathrm{H}_{\mathrm{C}} \mathrm{OF}-3$ as a $2 \mathrm{D}$ polymer network 

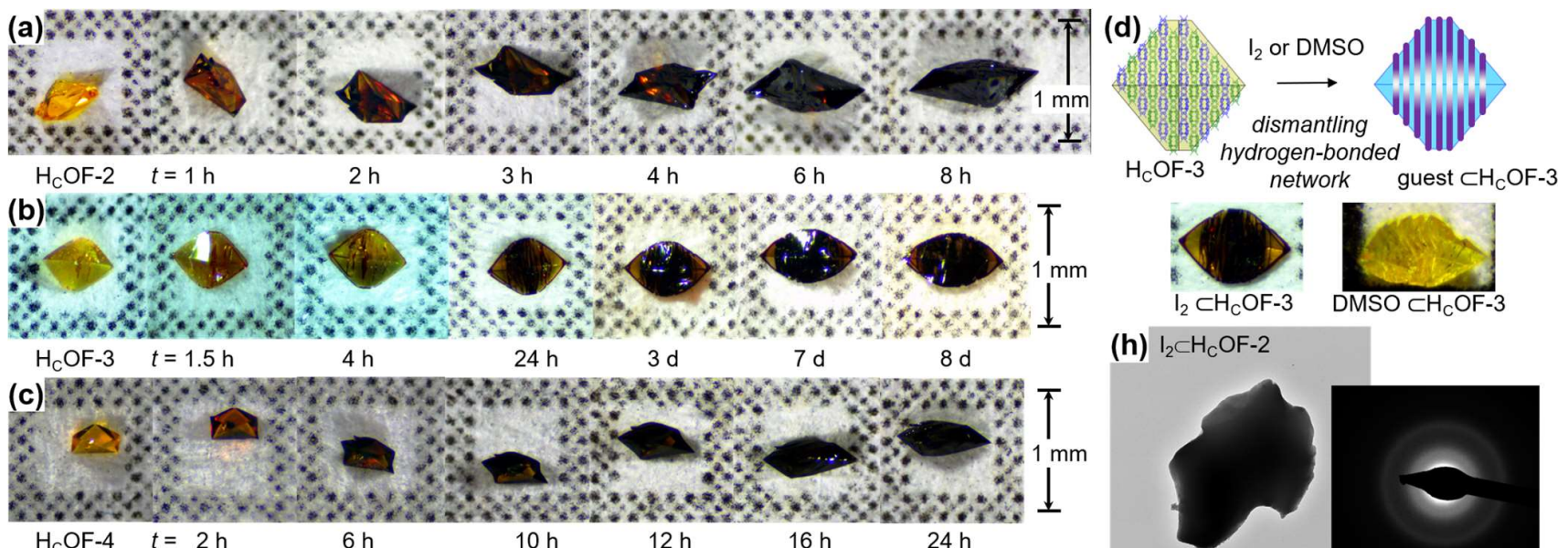

$4 \mathrm{~h}-24 \mathrm{~h}$

$3 d$

$7 d$

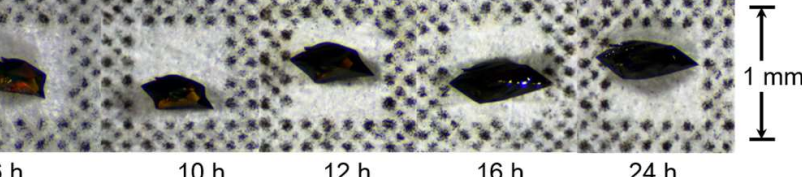

$10 \mathrm{~h}$

$12 \mathrm{~h}$

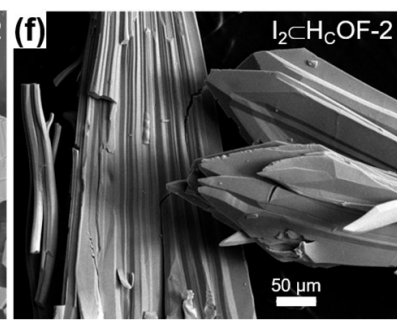

$16 \mathrm{~h}$

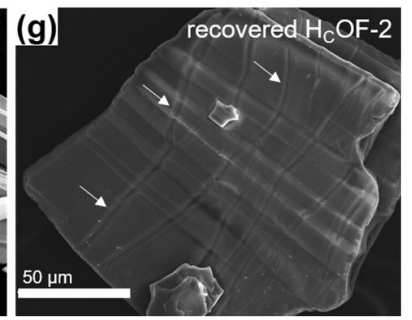

(h) $\mathrm{I}_{2} \subset \mathrm{H}_{\mathrm{C}} \mathrm{OF}-2$

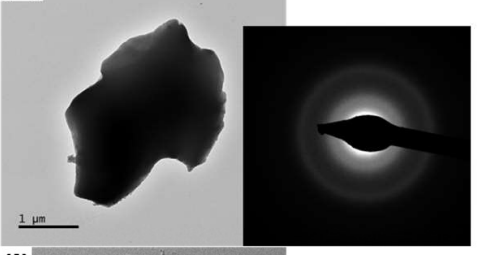

(i) recovered $\mathrm{H}_{\mathrm{C}} \mathrm{OF}-2$

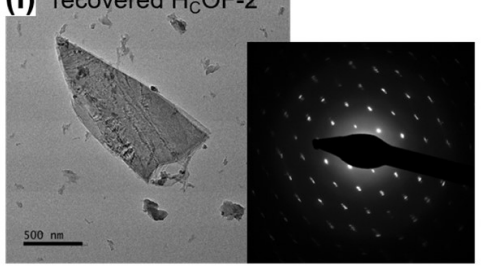

Figure 4. Anisotropic expansion and contraction of the $\mathrm{H}_{\mathrm{C}} \mathrm{OFs}$ crystal sizes upon guest sorption and structural elucidation of the dynamic behavior of $\mathrm{H}_{\mathrm{C}} \mathrm{OFs}$. (a-c) Images of crystal samples of (a) $\mathrm{H}_{\mathrm{C}} \mathrm{OF}-2$, (b) $\mathrm{H}_{\mathrm{C}} \mathrm{OF}-3$, and (c) $\mathrm{H}_{\mathrm{c}} \mathrm{OF}-4$ immersed in methanolic solution of iodine $(50 \mathrm{mM})$ for different times. The crystals were placed in a $1 \times 1 \mathrm{~mm}$ square box for size comparison. (d) Images of crystals of $\mathrm{I}_{2} \subset \mathrm{H}_{\mathrm{C}} \mathrm{OF}-3$ and DMSO $\subset \mathrm{H}_{\mathrm{C}} \mathrm{OF}-3$, and the simulated crystal morphology of an $\mathrm{H}_{\mathrm{C}} \mathrm{OF}-3$ crystal (void spaces are highlighted in yellow). (e-g) SEM images of (e) $\mathrm{H}_{\mathrm{C}} \mathrm{OF}-2$, (f) $\mathrm{I}_{2} \subset \mathrm{H}_{\mathrm{C}} \mathrm{OF}-2$, and (g) recovered $\mathrm{H}_{\mathrm{C}} \mathrm{OF}-2$ after iodine desorption. (h-i) TEM images and electron diffraction patterns of (h) $\mathrm{I}_{2} \subset \mathrm{H}_{\mathrm{C}} \mathrm{OF}-2$ and (i) $\mathrm{H}_{\mathrm{C}} \mathrm{OF}-2$ after $\mathrm{I}_{2}$ desorption.

(Figure 3f). When the four-connected (4-c) TPE core, threeconnected $(3-c)$ melamine moieties, and the dithioether moieties are defined as nodes, topological analysis suggests that (i) $\mathrm{H}_{\mathrm{C}} \mathrm{OF}-2$ is a 3-nodal 3,3,4-connected self-entangled $3 \mathrm{D}$ network with stoichiometry $(3-c)_{2}(3-c)_{2}(4-c)$ and point symbol of $(6.10 .12)_{2}\left(6.12^{2}\right)_{2}\left(6^{2} \cdot 10.12^{3}\right)$; and (ii) HcOF-3 is a 2D 3,4-connected net with stoichiometry $(3-c)_{2}(4-c) 2$ nodal $\left(7.8^{2}\right)_{2}\left(7^{3} .8^{3}\right)$ network, in which two neighboring packed layers of $\mathbf{1}$ are covalently crosslinked and extended along the [010] plane.

Due to their narrow pore openings and small voids, $\mathrm{H}_{\mathrm{C}} \mathrm{OFs}-2-4$ demonstrate no $\mathrm{N}_{2}$ uptake at $77 \mathrm{~K}$ and only adsorb small amounts of $\mathrm{CO}_{2}$ at $273 \mathrm{~K}$ (Figure S98). Remarkably, record-breaking aqueous iodine uptake capacities of $3.23 \pm 0.18 \mathrm{~g}, 3.00 \pm 0.09 \mathrm{~g}$, and $3.57 \pm 0.10 \mathrm{~g}$ of $\mathrm{I}_{2}$ per gram of $\mathrm{HcOF}_{\mathrm{c}} \mathrm{O}$ ere recorded ${ }^{32}$ for $\mathrm{H}_{\mathrm{c}} \mathrm{OFs}-2-4$ (Table S9), respectively, which exceed the previous record ${ }^{24}$ set by $\mathrm{H}_{\mathrm{C}} \mathrm{OF}-1$. Based on the adsorption values, the calculated van der Waals volumes ${ }^{33,34}$ of adsorbed $\mathrm{I}_{2}\left(26633 \AA^{3}\right.$ for $\mathrm{H}_{\mathrm{c}} \mathrm{OF}-2$ and $23878 \AA^{3}$ for $\left.\mathrm{H}_{\mathrm{C}} \mathrm{OF}-3\right)$ exceed the available void space of $\mathrm{H}_{\mathrm{c}} \mathrm{OF}-2$ and $\mathrm{H}_{\mathrm{C}} \mathrm{OF}-3$ by $473 \%$, and $668 \%$, respectively, requiring drastic volumetric expansion of these $\mathrm{H}_{\mathrm{C}} \mathrm{OF}$ crystals to accommodate $\mathrm{I}_{2}$ molecules as guests! When an $\mathrm{H}_{\mathrm{C}} \mathrm{OF}-2$ crystal $(\sim 0.50 \times 0.25 \mathrm{~mm}$, Figure $4 \mathrm{a})$ was immersed in a methanolic $I_{2}$ solution, ${ }^{35}$ gradual anisotropic expansion of the crystal and a directional $I_{2}$ diffusion path were observed. After $8 \mathrm{~h}$, the sample had expanded to a much larger size ( $0.50 \times 1.20 \mathrm{~mm}$ ) while maintaining a single cohesive shape and developing a visibly darker color. Similar anisotropic $\mathrm{I}_{2}-$ induced expansion was also recorded in $\mathrm{H}_{\mathrm{C}} \mathrm{OF}-4$ (Figure 4c). The $\mathrm{I}_{2}$-induced anisotropic size expansion of $\mathrm{H}_{\mathrm{C}} \mathrm{OF}-3$ is noticeably slower, and visible parallel linear $I_{2}$ diffusion paths were observed orthogonal to the axis of greatest expansion (Figure $4 \mathrm{~b}$ and $4 \mathrm{~d}$ ). Since the morphology of this $\mathrm{H}_{\mathrm{C}} \mathrm{OF}-3$ crystal matches well to its calculated Bravais-Friedel-Donnay-Harker (BFDH) morphology (Figure 4d), the experimental observation suggests that $I_{2}$ diffuses between the crosslinked 2D bilayers resulting in de-lamination of the crystal.

Scanning electron microscopy studies (SEM, Figure 4e-g) revealed that diamond-shaped crystals of $\mathrm{H}_{\mathrm{C}} \mathrm{OF}-2$ were transformed into bundles of $\mathrm{I}_{2} \subset \mathrm{H}_{\mathrm{C}} \mathrm{OF}-2$ as a result of the size expansion, and energy dispersive X-ray (EDX) spectra (Figure S56) confirmed the presence of large quantities of iodine. The dark crystal-like $\mathrm{I}_{2} \subset \mathrm{H}_{\mathrm{C}} \mathrm{OF}-2$ exhibited poorly defined diffraction patterns by transmission electron microscopy (TEM, Figure 4h) and powder X-ray diffraction (PXRD, Figure 5c), suggesting a crystalline-to-amorphous phase transition. The adsorbed iodine could be released by washing with DMSO, ethanol, and water, resulting in gradual size shrinking as the dark crystals turned to a light-red (Figure S74). The recovered $\mathrm{HcOF}_{\mathrm{C}} 2$ samples possess wrinkles (Figure $4 \mathrm{~g}$ ) generated by the expansion/contraction process and some of the recovered $\mathrm{H}_{\mathrm{C}} \mathrm{OF}-2$ samples in TEM analysis (Figure 4i) are found to recover their periodic alignment as shown in the electron diffraction pattern. Similar phenomena were also observed in $\mathrm{H}_{\mathrm{C}} \mathrm{OF}-3$ (Figure S57-61). 
(a)
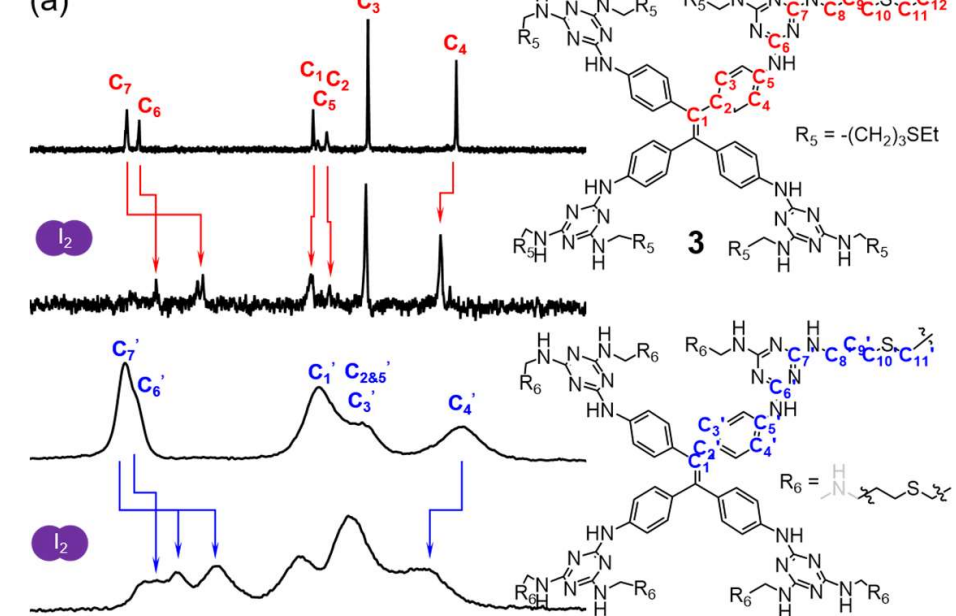

$\mathrm{H}_{\mathrm{C}} \mathrm{OF}-2$

(b)

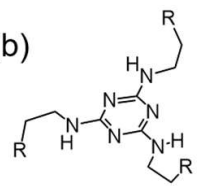

$4 \mathrm{R}=\mathrm{CH}_{2} \mathrm{SEt}$

$5 \mathrm{R}=\mathrm{H}$
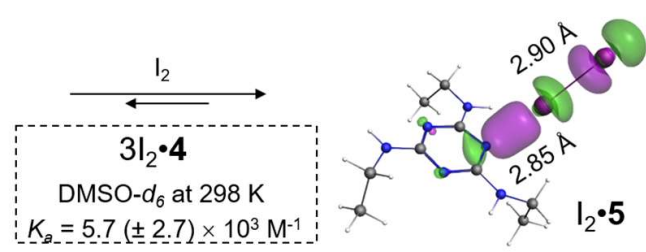

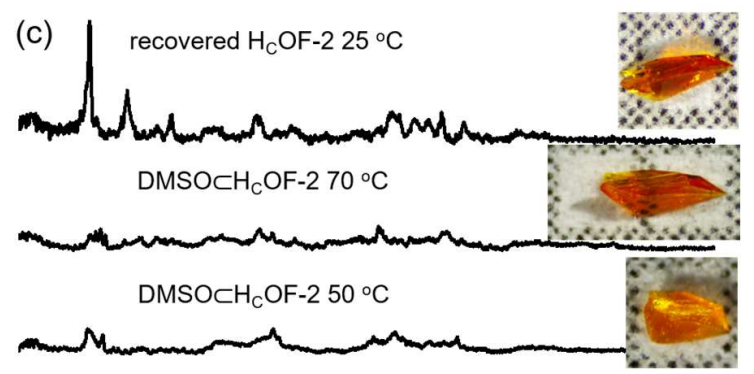

$3.2 \mathrm{~g} / \mathrm{g} \mathrm{I}_{2} \subset \mathrm{H}_{\mathrm{C}} \mathrm{OF}-2$
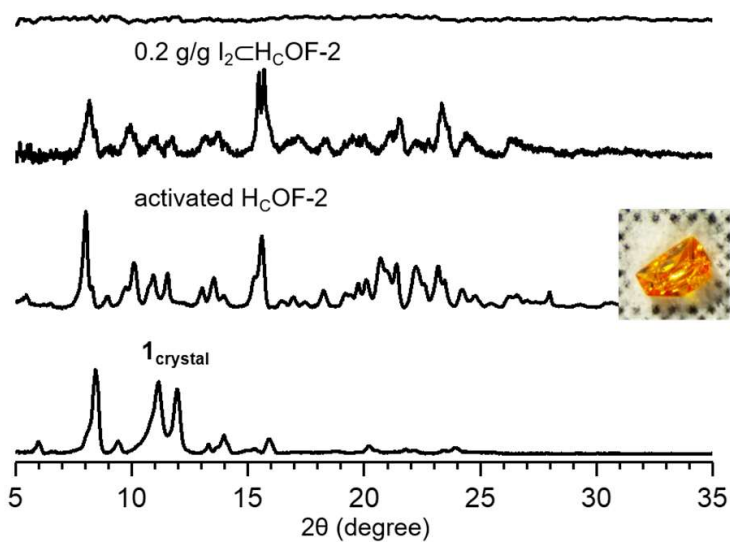

Figure 5. (a) Solution-phase ${ }^{13} \mathrm{C}$ NMR spectra of model compound 3 (top, $6.53 \mathrm{mM}$ ) and solid-state ${ }^{13} \mathrm{C}$ NMR spectra of $\mathrm{HcOF}-2$ (bottom) in the absence and presence of $\mathrm{I}_{2}$ (14.0 equivalent to 3 ). (b) Chemical structures of 4-5, binding affinity of $3 \mathrm{I}_{2}{ }^{\bullet 4}$, and DFT calculated $\mathrm{I}_{2} \cdot 5$ with calculated N-I and I-I bond distances of $2.85 \AA$ and $2.90 \AA$, respectively. (c) PXRD profiles of (from bottom up)

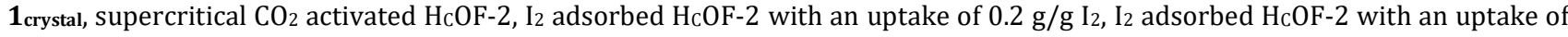
$3.2 \mathrm{~g} / \mathrm{g}$ of $\mathrm{I}_{2}$, DMSO-soaked $\mathrm{H}_{\mathrm{C}} \mathrm{OF}-2$ at $50{ }^{\circ} \mathrm{C}$, DMSO-soaked $\mathrm{H}_{\mathrm{C}} \mathrm{OF}-2$ at $70{ }^{\circ} \mathrm{C}$, and air cooled DMSO-soaked $\mathrm{H}_{\mathrm{C}} \mathrm{OF}-2$ at $25{ }^{\circ} \mathrm{C}$ after heating.

When $\mathrm{I}_{2}$ molecules were adsorbed in $\mathrm{H}_{\mathrm{C}} \mathrm{OFs}-2-4$, the carbon resonances assigned to the triazine ring and aliphatic crosslinkages shifted upfield (up to $15 \mathrm{ppm}$ ) in the solidstate ${ }^{13} \mathrm{C}$ NMR spectra (Figure $5 \mathrm{a}$ ), suggesting that the $\mathrm{I}_{2}$-induced crystal size expansion is attributed to a change of the local environment of the melamine motifs. The detailed $\mathrm{I}_{2}-$ framework interaction is revealed through the investigation of model compounds 3-5 with $\mathrm{I}_{2}$ (Figure $5 \mathrm{a}$ and $5 \mathrm{~b}$, Figure S80-83). In DMSO- $d_{6}, 3$ binds multiple $\mathrm{I}_{2}$ molecules, the - $\mathrm{NH}$ - proton resonances of the melamine moieties of $\mathbf{3}$ shift downfield, and triazine carbon resonances shift upfield, similar to those phenomena in $\mathrm{H}_{\mathrm{C}} \mathrm{OF}-2$. A strong binding affinity of $K_{\mathrm{a}}=5.7( \pm 2.7) \times 10^{3} \mathrm{M}^{-1}$ was measured between 4 and $\mathrm{I}_{2}$ (in 1:3 stoichiometry, Figure $5 \mathrm{~b}$ ) in DMSO- $d_{6}$ at $298 \mathrm{~K}$, despite the large excess of DMSO competing with I2. Density functional theory (DFT) calculations (Scheme S9, Table S10, Figures S78-79) revealed that strong halogen bonds are formed between the lone pair of triazine nitrogen atoms and $\sigma^{*}$ orbital of $\mathrm{I}_{2}$ in the $\mathrm{I}_{2} \bullet 5$ complex, with a high binding enthalpy ( $\sim 12 \mathrm{kcal} / \mathrm{mol}$ per N-I bond). The DFT and NMR studies suggest that, when $\mathrm{I}_{2}$ is adsorbed into $\mathrm{H}_{\mathrm{c}} \mathrm{OFs}$, the strong N-I halogen bonding interactions outcompete the original hydrogen-bonded network. The flexible crosslinkers in $\mathrm{H}_{\mathrm{C}} \mathrm{OFs}$ are thus stretched and - $\mathrm{NH}$ - moieties are rotated to expand the polymer network and accommodate more $\mathrm{I}_{2}$ molecules without breaking any covalent bonds.

When DMSO is employed as a weaker hydrogen bonding network disrupter, less extensive framework expansion and contraction of $\mathrm{H}_{\mathrm{C}} \mathrm{OFs}$ was observed (Figure 5c). Interestingly a temperature-gated crystal size expansion and contraction was observed when $\mathrm{H}_{\mathrm{C}} \mathrm{OF}$ crystals were soaked in DMSO, and the crystalline-to-amorphous and amorphous-to-crystalline phase transitions were recorded by PXRD (Figures 5c, S90-92). After heating $\mathrm{H}_{\mathrm{C}} \mathrm{OF}-2$ at $50{ }^{\circ} \mathrm{C}$, $\mathrm{H}_{\mathrm{C}} \mathrm{OF}-3$ at $70^{\circ} \mathrm{C}$, and $\mathrm{H}_{\mathrm{C}} \mathrm{OF}-4$ at $70{ }^{\circ} \mathrm{C}$ in DMSO, crystal samples of HcOF-2 expanded anisotropically (Figure 5c, inset), while the crystal samples of $\mathrm{H}_{\mathrm{C}} \mathrm{OF}-3$ de-laminated into sheets (Figure 4d). After cooling these crystal samples to room temperature, the long-range order of the molecular entities of $\mathrm{HcOFs}-2-4$ recovered as shown in their PXRD profiles (Figure 5c, S90-92). The different I2 uptake capacities and phase-change temperature in DMSO between $\mathrm{HcOF}_{\mathrm{C}} \mathrm{O}$ and $\mathrm{H}_{\mathrm{C}} \mathrm{OF}-3$ also highlights the significant contribution from the different crosslinking topologies, despite the common monomer crystal and identical hydrogen bonding network from which these $\mathrm{H}_{\mathrm{C}} \mathrm{OFs}$ are derived.

From a thermodynamic perspective, when the guest molecules are desorbed from the framework, the reformation of the hydrogen bonds between the melamine groups directs the framework recovery. Depending on the extensiveness of the framework expansion, the melamine groups may form kinetically stable, randomly oriented hydrogen bonding networks to maximize the network entropy rather than recovering to the highly ordered original form. This analysis highlights the important contribution from the flexible (disordered) crosslinkers. During the elastic expansion process, 
the flexible crosslinkers are stretched to entropically disfavored conformations. During the framework recovery process, the stretched flexible crosslinkers return to their disordered state and contribute positive entropy for the reformation of the highly ordered framework. Similar structures are also found in many proteins ${ }^{36-39}$, where the amorphous domain of the protein enables the rigid domain to dynamically alter its functions. Hence, although the co-existence of multiple conformations of the dithioether motifs in $\mathrm{H}_{\mathrm{c}} \mathrm{OFs}$ increases the complexity for SCXRD analysis, the integration of disordered linkages as molecular level 'amorphous domains' enables the elastic expansion and contraction of the framework materials. In addition, the guest-activated dormant voids in $\mathrm{H}_{\mathrm{C}} \mathrm{OFs}$ are inversely related to the crosslinking density of $\mathrm{H}_{\mathrm{C}} \mathrm{OFs}$, similar to the swelling behavior of traditional crosslinked polymer networks. ${ }^{40}$ For example, $\mathrm{H}_{\mathrm{C}} \mathrm{OF}-2$ possesses a higher $\mathrm{I}_{2}$ adsorption capacity compared to the more densely crosslinked $\mathrm{H}_{\mathrm{C}} \mathrm{OF}-1$, despite the permanent voids of $\mathrm{H}_{\mathrm{C}} \mathrm{OF}-2$ being significantly smaller than those of $\mathrm{H}_{\mathrm{C}} \mathrm{OF}-1$.

\section{Conclusions}

In summary, we demonstrated a topochemical strategy to synthesize single crystalline porous organic frameworks $\mathrm{H}_{\mathrm{C}} \mathrm{OFs}-2-4$ with divergent crosslinking topologies through a single-crystal to single-crystal transformation. Although the tetraphenylethylene and melamine moieties of these $\mathrm{H}_{\mathrm{C}} \mathrm{OFs}$ remain largely undisturbed compared to their parent molecular crystal, the disordered dithioether linkages generated after photo-crosslinking obstruct the molecular-level structural analysis of current, and likely future, $\mathrm{H}_{\mathrm{c}} \mathrm{OFs}$ consisting of flexible crosslinkers. We overcome this obstacle by (1) synthesizing two isostructural single-crystalline polymer analogues to the HcOFs (P5 and P6), followed by (2) investigating the crosslinking outcomes using crystal samples with partially blocked allyl sites. The unveiled topological assignments of $\mathrm{HcOF}-2$ and $\mathrm{HcOF}-3$ suggest them to be a self-entangled 3D network and a 2D-bilayer crosslinked polymer, respectively. $\mathrm{H}_{\mathrm{C}} \mathrm{OFs}-2-4$ demonstrated superior iodine uptake capacities (up to $3.5 \mathrm{~g} / \mathrm{g}$ ) and significant visible crystal size expansions (> $200 \%$ ) in an aqueous environment, and the different guest sorption capacities and morphology changes of the $\mathrm{H}_{\mathrm{c}} \mathrm{OFs}$ comes from the different crosslinking topologies. These results suggest that the flexible dithioether linkages in $\mathrm{H}_{\mathrm{C}} \mathrm{OFs}$ can give rise to a much larger dormant void activated by the presence of guest molecules. The binding energy difference between the substrate-framework ( $\mathrm{I}_{2}$ with melamine moieties) and the hydrogen-bonded framework of $\mathrm{H}_{\mathrm{C}} \mathrm{OFs}$ determines the energy barrier to activate the guest-induced voids, as observed in their temperature-gated DMSO sorption behaviors. Our investigations not only point out that incorporating flexible crosslinking moieties in $\mathrm{HcOFs}_{\mathrm{C}}$ is critical to facilitate large dynamic structural variation without sacrificing the highly ordered structure of $\mathrm{H}_{\mathrm{c}} \mathrm{OFs}$, it also illustrated a clear structure property relationship in $\mathrm{H}_{\mathrm{C}} \mathrm{OFs}$, revealing that the crosslinking topology plays a key role in determining the guest-induced void space. We believe that these research outcomes not only demonstrate a topologically-controlled synthesis of $\mathrm{H}_{\mathrm{C}} \mathrm{OF}$ materials with integrated high structural order and flexibility, but, more importantly, reveal a molec- ular-level understanding of the roles of 'ordered' and 'disordered' segments of $\mathrm{HcOFs}_{\mathrm{c}} \mathrm{On}$ relation to their dynamic guest sorption behaviors. Such insights lay the foundation for future $\mathrm{HcOF}_{\mathrm{C}} \mathrm{Oesigns}$ and, more broadly, the design of crystalline porous organic framework materials with dynamic sorption behaviors for both high uptake capacity and selectivity.

\section{ASSOCIATED CONTENT}

Supporting Information. The Supporting Information is available free of charge via the Internet at http://pubs.acs.org. Syntheses and characterizations of monomers, HcOFs and polymers, SCSC transformations, single-crystal and powder X-ray diffraction analysis, guest sorption investigations, DFT calculations, and NMR studies (PDF)

Crystal structures (CIF)

\section{AUTHOR INFORMATION}

\section{Corresponding Author}

* Chenfeng.ke@dartmouth.edu

\section{Author Contributions}

$\$$ These authors contributed equally.

\section{ACKNOWLEDGMENT}

The authors acknowledge funding support from the NSF CAREER award (1844920), and the startup funds from Dartmouth College. We thank Dr. Aaron Finke for his assistance in solving the crystal structure of $\mathbf{2}$. We thank Prof. Dieter A. Schlüter, Mr. Gregor Hofer at ETH Zurich, Dr. Olivier Blacque at the University of Zurich for their assistance in collecting preliminary X-ray data and helpful discussions. Davide M Proserpio thanks the Università degli Studi di Milano for the transition grant PSR2015-1718. Eugeny V. Alexandrov thanks Russian Science Foundation (grant No. 18-73-10116) for financial support of the development of methods for topological analysis.

\section{REFERENCES}

(1) Brunet, P.; Demers, E.; Maris, T.; Enright, G. D.; Wuest, J. D. Designing permeable molecular crystals that react with external agents to give crystalline products. Angew. Chem. Int. Ed. 2003, 42, 5303-5306.

(2) Beaudoin, D.; Maris, T.; Wuest, J. D. Constructing monocrystalline covalent organic networks by polymerization. Nat. Chem. 2013, 5, 830-834.

(3) Evans, A. M.; Parent, L. R.; Flanders, N. C.; Bisbey, R. P.; Vitaku, E.; Kirschner, M. S.; Schaller, R. D.; Chen, L. X.; Gianneschi, N. C.; Dichtel, W. R. Seeded growth of single-crystal two-dimensional covalent organic frameworks. Science 2018, 361, 52-57.

(4) Ma, T.; Kapustin, E. A.; Yin, S. X.; Liang, L.; Zhou, Z.; Niu, J.; Li, L.-H.; Wang, Y.; Su, J.; Li, J.; Wang, X.; Wang, W. D.; Wang, W.; Sun, J.; Yaghi, O. M. Single-crystal X-ray diffraction structures of covalent organic frameworks. Science 2018, 361, 48-52.

(5) Yuan, S.; Feng, L.; Wang, K.; Pang, J.; Bosch, M.; Lollar, C.; Sun Y.; Qin, J.; Yang, X.; Zhang, P.; Wang, Q.; Zou, L.; Zhang, Y.; Zhang, L.; Fang, Y.; Li, J.; Zhou, H.-C. Stable metal-organic frameworks: design, synthesis, and applications. Adv. Mater. 2018, 30, 1704303.

(6) Wegner, G. Solid-state polymerization mechanisms. Pure \& Appl. Chem. 1977, 49, 443-454.

(7) Sun, A.; Lauher, J. W.; Goroff, N. S. Preparation of poly(diiododiacetylene), an ordered conjugated polymer of carbon and iodine. Science 2006, 312, 1030-1034. 
(8) Kissel, P.; Erni, R.; Schweizer, W. B.; Rossell, M. D.; King, B. T.; Bauer, T.; Götzinger, S.; Schlüter, A. D.; Sakamoto J. A two-dimensional polymer prepared by organic synthesis. Nat. Chem. 2012, 4, 287-291.

(9) Kory, M. J.; Wörle, M.; Weber, T.; Payamyar, P.; van de Poll, S. W.; Dshemuchadse, J.; Trapp, N.; Schlüter, A. D. Gram-scale synthesis of two-dimensional polymer crystals and their structure analysis by X-ray diffraction. Nat. Chem. 2014, 6, 779-784.

(10) Chen, Y.; Shi, Z.-L.; Wei, L.; Zhou, B.; Tan, J.; Zhou, H.-L.; Zhang, Y. B. Guest-dependent dynamics in a 3D covalent organic framework. J. Am. Chem. Soc. 2019, 141, 3298-3303.

(11) Ma, Y. X.; Li, Z. J.; Wei, L.; Ding, S.-Y.; Zhang, Y. B.; Wang, W. A dynamic three-dimensional covalent organic framework. J. Am. Chem. Soc. 2017, 139, 4995-4998.

(12) Horike, S.; Shimomura, S.; Kitagawa, S. Soft porous crystals. Nat. Chem. 2009, 1, 695.

(13) Horcajada, P.; Salles, F.; Wuttke, S.; Devic, T.; Heurtaux, D.; Maurin, G.; Vimont, A.; Daturi, M.; David, O.; Magnier, E.; Stock, N.; Filinchuk, Y.; Popov, D.; Riekel, C.; Férey, G.; Serre C. How linker's modification controls swelling properties of highly flexible iron(III) dicarboxylates MIL-88. J. Am. Chem. Soc. 2011, 133, 17839-17847.

(14) Schneemann, A.; Bon, V.; Schwedler, I.; Senkovska, I.; Kaskel, S.; Fischer R. A. Flexible metal-organic frameworks. Chem. Soc. Rev. 2014, 43, 6062-6096.

(15) Bennett, T. D.; Cheetham, A. K.; Fuchs, A. H.; Coudert, F.-X. Interplay between defects, disorder and flexibility in metal-organic frameworks. Nat. Chem. 2017, 9, 11-16.

(16) Zhang, L.; Bailey, J. B.; Subramanian, R. H.; Groisman, A.; Tezcan, F. A. Hyperexpandable, self-healing macromolecular crystals with integrated polymer networks. Nature 2018, 557, 86-91.

(17) Liu, Y.; Ma, Y.; Zhao, Y.; Sun, X.; Gándara, F.; Furukawa, H.; Liu, Z.; Zhu, H.; Zhu, C.; Suenaga, K.; Oleynikov, P.; Alshammari, A. S.; Zhang, X.; Terasaki, O.; Yaghi O. M. Weaving of organic threads into a crystalline covalent organic framework. Science 2016, 351, 365-369.

(18) Zhao, C.; Diercks, C. S.; Zhu, C.; Hanike, N.; Pei, X.; Yaghi O. M. Urea-linked covalent organic frameworks. J. Am. Chem. Soc. 2018, 140, 16438-16441.

(19) Brunet, P.; Simard, M.; Wuest, J. D. Molecular tectonics. Porous hydrogen-bonded networks with unprecedented structural integrity. J. Am. Chem. Soc. 1997, 119, 2737-2738.

(20) He, Y.; Xiang, S.; Chen, B. A microporous hydrogen-bonded organic framework for highly selective $\mathrm{C}_{2} \mathrm{H}_{2} / \mathrm{C}_{2} \mathrm{H}_{4}$ separation at ambient temperature. J. Am. Chem. Soc. 2011, 133, 14570-14573.

(21) Wang, H.; Li, B.; Wu, H.; Hu, T.-L.; Yao, Z.; Zhou, W.; Xiang, S.; Chen, B. A flexible microporous hydrogen-bonded organic framework for gas sorption and separation. J. Am. Chem. Soc. 2015, 137, 9963-9970.

(22) Han, B.; Wang, H.; Wang, C.; Wu, H.; Zhou, W.; Chen, B.; Jiang, J. Postsynthetic metalation of a robust hydrogen-bonded organic framework for heterogeneous catalysis. J. Am. Chem. Soc. 2019, 141, 8737-8740.

(23) Hisaki, I.; Xin, C.; Takahashi, K.; Nakamura, T. Designing hydrogen-bonded organic frameworks (HOFs) with permanent porosity. Angew. Chem. Int. Ed. 2019, doi:10.1002/anie.201902147.

(24) Lin, Y.; Jiang, X.; Kim, S. T.; Alahakoon, S. B.; Hou, X.; Zhang, Z.; Thompson, C. M.; Smaldone, R. A.; Ke, C. An elastic hydrogen- bonded cross-linked organic framework for effective iodine capture in water. J. Am. Chem. Soc. 2017, 139, 7172-7175.

(25) Waller, P. J.; Gandara, F.; Yaghi, O. M. Chemistry of covalent organic frameworks. Acc. Chem. Res. 2015, 48, 3053-3063.

(26) Huang, N.; Wang, P.; Jiang, D. Covalent organic frameworks: a materials platform for structural and functional designs. Nat. Rev. Mater. 2016, 1, 16068.

(27) Bisbey, R. P.; Dichtel, W. R. Covalent organic frameworks as a platform for multidimensional polymerization. ACS Cent. Sci. 2017, 3, 533-543.

(28) Jin, Y.; Hu, Y.; Zhang, W. Tessellated multiporous two-dimensional covalent organic frameworks. Nat. Rev. Chem. 2017, 1 0056.

(29) Wang, W.; Schlüter, A. D. Synthetic 2D polymers: A critical perspective and a look into the future. Macromol. Rapid Commun 2019, 40, 1800719.

(30) In comparison, if the crosslinker diffusion process is uncontrolled, crystal samples possessing a ratio of EDT/1 = 3.30:1 were obtained, in which insoluble crystals formed rapidly after the addition of the EDT before photo-irradiation.

(31) 1,6-hexanedithiol, HDT, was employed to generate P8.

(32) The iodine uptake capacities of $\mathrm{H}_{\mathrm{C}} \mathrm{OFs}-2-4$ were measured in aqueous $\mathrm{KI}_{3}$ solutions at room temperature, which reversibly release $\mathrm{I}_{2}$ upon $\mathrm{H}_{\mathrm{C}} \mathrm{OFs}$ ' adsorption. These iodine uptake capacities have been cross verified by gravimetric, elemental, and thermogravimetric analysis, which holds the record of iodine adsorption in the aqueous environment. A higher iodine uptake capacity of 6.2 $\mathrm{g} / \mathrm{g}$ has been reported in iodine gas vapor, see Wang, P.; Xu, Q.; Li, Z.; Jiang, W.; Jiang, Q.; Jiang, D. Exceptional iodine capture in 2D covalent organic frameworks. Adv. Mater. 2018, 30, 1801991. Related iodine adsorption values obtained using other porous materials are summarized in Table S11 in the Supporting Information.

(33) Van Bolhuis, F.; Koster, P. B.; Migchelsen, T. Refinement of the crystal structure of iodine at 110 K. Acta Cryst. 1967, 23, 90-91.

(34) Walbaum, C.; Pantenburg, I.; Meyer, G. Iodine molecules included in the structure of Dibenzo-24-Crown-8,(I2)@(db24c8) Crystals 2011, 1, 215-219.

(35) The adsorption kinetics in methanolic solutions are slower to help maintaining the shape of the crystal without severe shat tering

(36) Boehr, D. D.; Nussinov, R.; Wright, P. E. The role of dynamic conformational ensembles in biomolecular recognition. Nat. Chem. Biol. 2009, 5, 789-796.

(37) Hartl, F. U.; Bracher, A.; Hayer-Hartl, M. Molecular chaperones in protein folding and proteostasis. Nature 2011, 475, 324332 .

(38) Ma, B.; Tsai, C.-J.; Haliloğlu, T.; Nussinov, R. Dynamic allostery: linkers are not merely flexible. Structure 2011, 19, 907-917.

(39) van der Lee, R.; Buljan, M.; Lang, B.; Weatheritt, R. J.; Daughdrill, G. W.; Dunker, A. K.; Fuxreiter, M.; Gough, J.; Gsponer, J.; Jones, D. T.; Kim, P. M.; Kriwacki, R. W.; Oldfield, C. J.; Pappu, R. V.; Tompa P.; Uversky, V. N.; Wright, P. E.; Babu, M. M. Classification of intrinsically disordered regions and proteins. Chem. Rev. 2014, 114 6589-6631.

(40) Nandi, S.; Winter, H. H. Swelling behavior of partially crosslinked polymers: a ternary system. Macromolecules 2005, 38 4447-4455 
Table of Contents

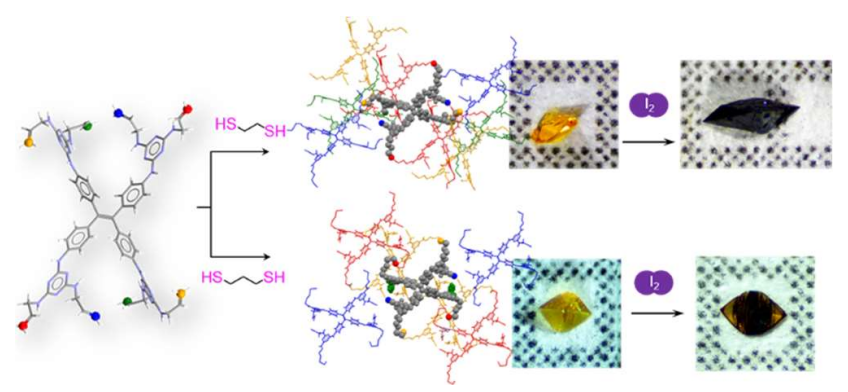

